\title{
OPEN
}

\section{Author Correction: Spotted phenotypes in horses lost attractiveness in the Middle Ages}

Saskia Wutke, Norbert Benecke, Edson Sandoval-Castellanos, Hans-Jürgen Döhle, Susanne Friederich, Javier Gonzalez, Jón Hallsteinn Hallsson, Michael Hofreiter, Lembi Lõugas, Ola Magnell, Arturo Morales-Muniz, Ludovic Orlando, Albína Hulda Pálsdóttir, Monika Reissmann, Matej Ruttkay, Alexandra Trinks \& Arne Ludwig

Correction to: Scientific Reports https://doi.org/10.1038/srep38548, published online 07 December 2016

The Acknowledgements section in this Article is incomplete.

“This work was funded by the Deutsche Forschungsgemeinschaft (LU 852/7-4). We thank Pavel Kosintsev for ancient horse samples from the Caspian Sea region. We thank Dietmar Lieckfeldt and Melanie Pruvost for their assistance as well as Dorina Lenz for helping with the data analyses. We also acknowledge the valuable comments from Dolores Carmen Morales-Muñiz about the Riders of the Apocalypse."

should read:

“This work was funded by the Deutsche Forschungsgemeinschaft (LU 852/7-4). We thank Pavel Kosintsev for ancient horse samples from the Caspian Sea region. We thank Dietmar Lieckfeldt and Melanie Pruvost for their assistance as well as Dorina Lenz for helping with the data analyses. We also acknowledge the valuable comments from Dolores Carmen Morales-Muñiz about the Riders of the Apocalypse. This project has received funding from the European Research Council (ERC) under the European Union's Horizon 2020 research and innovation programme (grant agreement No. 681605)."

(i) Open Access This article is licensed under a Creative Commons Attribution 4.0 International License, which permits use, sharing, adaptation, distribution and reproduction in any medium or format, as long as you give appropriate credit to the original author(s) and the source, provide a link to the Creative Commons license, and indicate if changes were made. The images or other third party material in this article are included in the article's Creative Commons license, unless indicated otherwise in a credit line to the material. If material is not included in the article's Creative Commons license and your intended use is not permitted by statutory regulation or exceeds the permitted use, you will need to obtain permission directly from the copyright holder. To view a copy of this license, visit http://creativecommons.org/licenses/by/4.0/.

(C) The Author(s) 2020 